\section{UK, ESA and Integral}

SIR - Giovanni Bignami (Nature 374, $110 ; 1995)$ accuses the United Kingdom, through the Particle Physics and Astronomy Research Council (PPARC), of "reneging on an agreement with the rest of Europe", by failing to fund a substantial payload contribution to the Integral mission. In the same issue of Nature, Professor J. L. Culhane and others express the concern of UK scientists who expected to play a major role in Integral, adding that the anticipated costs of UK participation "were well known and [had] not changed substantially". Perhaps I may be allowed to offer some background to this sad chapter in UK space science.

As the first chief executive of PPARC (and a space scientist by training), I am acutely aware of the damage to a section of the UK community, to the Integral project, and to Britain's reputation as a reliable partner, resulting from our inability to play a substantial role in Integral. I also appreciate the impact on UK industry from the lost contracts in high-technology areas. However, the commitments and funding inherited by PPARC when it assumed responsibility for UK space science from the Science and Engineering Research Council a year ago led inevitably to the present outcome.

Funding of the 'expected' level of payload development by UK groups was estimated at $£ 21$ million. In contrast, the PPARC budget a year ago included only $£ 3$ million for that purpose, over the years 1995-98, with some expectation of an additional $£ 7-£ 8$ million based on the assumption that PPARC's funding would be maintained, in real terms, over the following two years. Following its first full programme review, in September 1994, the PPARC council concluded that very limited funds were indeed likely to be available for the next two ESA missions, Integral and Rosetta. In an attempt to avoid reneging on agreements with colleagues elsewhere in Europe, I then made sure that the UK space science community and the European Space Agency (ESA) had early warning of our difficulties. Unfortunately, it does seem that these warnings went unheeded in the extensive proposals made to ESA in December.

As to the future, I strongly agree with Culhane et al. that it is vital that PPARC finds some way to ensure that the Integral debacle does not recur with subsequent ESA missions. Otherwise, UK membership of ESA would be called into question, as we became increasingly unable to enjoy the scientific and technological benefits of our subscription to this 'world class' space science programme.

To avoid such an outcome, which would be a disaster for UK space science, a considerable loss to an important sector of
UK industry, and damaging to the ESA programme itself, PPARC is actively working with its space partners in the UK and Europe to find additional funds for exploitation of future ESA spaceflight opportunities.

\section{K. A. Pounds}

(Chief Executive)

Particle Physics and Astronomy

Research Council,

Polaris House, North Star Avenue, Swindon, Wiltshire SN2 1SZ, UK

\section{Dissolubility of federations}

SIR - While the bells of peace in Northern Ireland are beginning to peal and to be heard in Europe, your article on Russia's heavy-handed approach to separatist tendencies in Chechenia and the principle of federalism could not have been more timely (Nature 373, 89-90; 1995). The continuation of the tradition of subjugation of people within sovereign states goes back a long way, particularly in Europe where countries are redefined after major wars. The concept of federalism means different things to different people and so is prone to misinterpretation. For those living in a federal state, it is an instrument of government that maintains cultural identity yet provides a central government to function economically and politically. The examples you have given of the Flemish and Walloon regions in federal Belgium are a paradigm of the two levels of government. But your points concerning Switzerland are not quite accurate.

Switzerland, although called a confederation, is since 1848 a federal state. A confederation is by definition an association of sovereign states ceding certain competencies to common bodies (for example, the Confederated States of America in 1861-65), whereas federal states such as Austria, Belgium, Germany, Switzerland or the United States of America today are composed of traditional/ cultural territorial entities ceding to the federal government only functions such as foreign policy, currency and defence. Thanks to the federal system, the region of northern Jura, with a mainly Roman Catholic population, was able to separate from the canton of Bern and to become an independent new Swiss canton - whereas the southern Jura, mainly Protestant, remained with the canton of Bern. An example worthy to be given in the right context.

In conclusion, the question of how small states can survive can be answered by the example of Iceland. This proud nation of 300,000 people manages its place well in
Europe and has in the past taught lessons in independence to large states (the cod war!). The 25 years of military occupation of Northern Ireland by British troops only demonstrates that a central government cannot force cohesion between different communities within a country and therefore, maybe, a federal system might be better way for the future.

S. S. Baig

M. Hallen

Brussels, Belgium

\section{War on anti-science}

SIR - Like many other scientists, I agree with John Maddox (Nature 368, 185; 1994) that we have to be more active when struggling against the forces of antiscience.

In Russia there is now a rapid growth of publications and television and radio programmes dedicated to anti-science. Real scientific publications and broadcasting programmes seem of little account in comparison with the avalanche of antiscience. This is very dangerous for the education of the young in the evaluation of scientific and technical achievements and for the future of science and development of society as a whole.

As I see it, there are at least three reasons. (1) The press in Russia is no longer controlled by government censorship. As a result, all previously 'hidden' areas are blossoming in contrast to traditional ones. (2) Those working in astrology, alternative medicine and extraterrestrial visitors are younger, more active, and more adaptable. They know the tastes of a wide public. (3) The language of anti-science is simple and more understandable for many people; anti-science speaks with confidence, whereas real science recognizes the limitations of knowledge.

So we need to find ways to popularize science and its new achievements. We need outstanding scientists who can explain complicated things using simple examples to attract the attention of young people to the beauties and secrets of nature.

It is necessary to demonstrate the difference between fact and fantasy, truth and lies, scientific forecasts and astrological horoscopes. We need to talk to the public in understandable terminology and with impressive examples. Television and radio companies would find time for useful scientific programmes if they were offered. It should not be a quick attack but a long siege, promising to provide good results many years ahead.

Boris Shmakin

Inst. of Geochemistry,

PO Box 9019.

Irkutsk-33,

Russia 664033 